\title{
Partial characterization of the embryo-derived platelet-activating factor in mice
}

\author{
C. O'Neill* \\ Department of Veterinary Physiology, University of Sydney, New South Wales 2006, and \\ Department of Biological Sciences, University of Newcastle, New South Wales 2038, Australia
}

\begin{abstract}
Summary. The platelet-activating factor (PAF) produced by mouse embryos showed similar kinetics of action and dose-response curve, in a bioassay, as did 1-0-alkyl-2acetyl-sn-glyceryl-3-phosphocholine (PAF-acether). The activity of the embryoderived PAF was not affected by inhibitors of the ADP (pyruvate kinase with phosphoenol pyruvate) or cyclo-oxygenase (indomethacin) pathways of platelet activation. Chlorpromazine, an inhibitor of the PAF-acether pathway of platelet activation, caused a significant inhibition of the effects of embryo-derived PAF. Phospholipases $A_{2}, C$ and $D$ significantly inhibited the activity while lipase had no effect, suggesting a phospholipid structure. All the embryo-derived PAF was found in the chloroform fraction after chloroform:methanol $(2: 1 \mathrm{v} / \mathrm{v})$ extraction, as was PAF-acether. Both factors migrated at a similar rate $\left(R_{\mathrm{f}} 0 \cdot 10-0 \cdot 12\right)$ on silica thin-layer chromatography (chloroform:methanol:water; $65: 35: 4$ by vol.). The embryo-derived PAF therefore displays chemical, biochemical and physiological properties similar to those of PAFacether.
\end{abstract}

\section{Introduction}

The initial maternal response to conception in mice was shown to be platelet activation, resulting in splenic contraction and mild thrombocytopenia (O'Neill, 1985a). This response to the presence of the zygote occurred within hours of fertilization. Early pregnancy-associated thrombocytopenia was not a consequence of the activation of the fluid phase of the blood coagulation cascade or of the maternal immunological recognition of the embryo: the preimplantation mouse embryo produced a soluble platelet-activating factor in vitro that had a temporal profile of induction of thrombocytopenia that was similar and a dose-response that was parallel to that caused by the platelet-activating factor, 1-0-alkyl-2-acetyl-sn-glyceryl-3-phosphocholine (PAF-acether) (O'Neill, 1985b). Further characterization of the embryo-derived platelet-activating factor was carried out and its biochemical and physiological characteristics were compared with those of PAF-acether.

\section{Materials and Methods}

Mice of the Quackenbush strain were exposed to light from 07:30 h to 21:30 h. Females, 6-8 weeks of age, were induced to superovulate by intraperitoneal (i.p.) injection of 5-10 i.u. PMSG (Folligon: Intervet, Boxmeer, The Netherlands) given at 15:00-17:00 h, followed 46-50 h later by

\footnotetext{
* Present address: IVF Laboratory, Department of Obstetrics and Gynaecology, University of Sydney, Royal North Shore Hospital, St Leonards, New South Wales 2065, Australia.
} 
an i.p. injection of 5-10 i.u. hCG (Chorulon: Intervet). After the second injection females were placed with fertile or vasectomized males and checked the following morning for copulation plugs (= Day 1 of pregnancy). On Day 2 embryos at the 8-16-cell stage, or unfertilized eggs, were collected from the oviducts of pregnant or pseudopregnant mice respectively. Unfertilized eggs and all morphologically normal embryos were pooled and groups of 30 were placed in $200 \mu \mathrm{l}$ Medium $\mathrm{W}_{1}$ containing $3 \mathrm{mg} \mathrm{BSA} / \mathrm{ml}$ (O'Neill \& Quinn, 1981) in disposable Petri dishes (Sterilin Ltd, Teddington, Middlesex, U.K.) for $24 \mathrm{~h}$. After culture the embryos or eggs were removed and the culture medium was frozen immediately.

\section{Bioassay for the embryo-derived platelet-activating factor}

The assay was carried out as previously described (O'Neill, 1985b). Briefly, medium or test substances were given as a single i.p. injection $(300 \mu \mathrm{l})$ into splenectomized mice. Platelet counts were performed immediately before and $30 \mathrm{~min}$ after injection. Animals were bled under light anaesthesia from the peri-orbital plexus and $10 \mu \mathrm{l}$ blood were diluted into $2 \mathrm{ml}$ ammonium oxalate $(1 \% \mathrm{w} / \mathrm{v})$. In each assay, samples of PAF-acether were run as positive controls.

PAF-acether (Calbiochem-Behring, Aust. Pty Ltd, Sydney, Australia) was resuspended in chloroform:methanol $(2: 1, \mathrm{v} / \mathrm{v})$ under $\mathrm{N}_{2}$ and was then diluted to $3.3 \mu \mathrm{g} / \mathrm{ml}$ in phosphate-buffered saline (pH 7.4) containing 0.25\% BSA (Commonwealth Serum Laboratories, Melbourne, Australia).

\section{Experiment 1}

The aim of this experiment was to determine whether inhibitors of the three pathways of platelet activation could block the platelet-activating effects of the embryo culture medium.

Indomethacin (Sigma Chemical Co., St Louis, MO, U.S.A.) was prepared as a $1 \mathrm{ml}$ solution in ethanol and then diluted to $10 \mu \mathrm{M}$ in $0.154 \mathrm{M}-\mathrm{NaCl}$. Various volumes of this solution $(10,20$ and $40 \mu \mathrm{l})$ were mixed with $300 \mu \mathrm{l}$ of control medium, embryo culture medium or PAF-acether and the solutions were tested in the mouse bioassay.

Following the method of Haslam (1964), stock solutions of $28 \mathrm{~mm}$-phosphoenol pyruvate (Calbiochem-Behring) and $300 \mathrm{U}$ pyruvate kinase/ml (EC 2.7.1.40: Calbiochem-Behring) in Medium $W_{1}$ were prepared. Some $(10 \mu \mathrm{l})$ of each stock was added to $200 \mu$ l of control medium, embryo culture medium or PAF-acether. The solutions were incubated at $37^{\circ} \mathrm{C}$ for 30 min before injection into splenectomized mice.

Chlorpromazine $\mathrm{HCl}$ (Chlorpromazine injection B.P., David Bull Laboratories Pty Ltd, Mulgrave, Victoria) was mixed with Medium $W_{1}$ to give a final concentration of 150,300 and $450 \mu \mathrm{g} / \mathrm{ml}$. Aliquants $(200 \mu \mathrm{l})$ of other solutions were tested in splenectomized mice.

\section{Experiment 2}

Structural analysis of PAF-acether using phospholipases and lipase was described by Benveniste, Le Couedic, Polonsky \& Tence (1977), and similar studies were performed on embryo-derived PAF. Control and embryo culture media were treated with the following enzymes at a final concentration of 0.5 i.u./ml: phospholipase $A_{2}$ (EC 3.1.1.4: from pig pancreas; Sigma); phospholipase C (EC 3.1.4.3: from B. cereus; Sigma); phospholipase D(EC 3.1.4.4: from cabbage; Sigma); and lipase (EC 3.1.1.3: pancreas; Calbiochem-Behring). Phospholipases $\mathrm{A}_{2}$ and $\mathrm{C}$ were incubated for $30 \mathrm{~min}$ at $37^{\circ} \mathrm{C}$ with regular agitation. Phospholipase $\mathrm{D}$ was incubated for $1 \mathrm{~h}$ at room temperature and lipase was left for $2.5 \mathrm{~h}$ at $37^{\circ} \mathrm{C}$ with constant agitation. Immediately after treatment, the media were injected into splenectomized mice. 


\section{Experiment 3}

Extraction of the lipid fraction of culture medium was carried out as described by Lotner, Lynch, Betz \& Henson (1980). Culture media were extracted with a chloroform:methanol:water (6:6:5.4, by volume) system. Methanol (A.R. grade, Ajax Chemical Co., Australia) was added to the culture medium, or to the PBS-BSA containing PAF-acether, in a ratio of $6: 4(\mathrm{v} / \mathrm{v})$. The contents were mixed at room temperature for $45 \mathrm{~min}$. The protein was precipitated by the methanol and removed by centrifugation at $4000 \mathrm{~g}$ for $20 \mathrm{~min}$ at $4^{\circ} \mathrm{C}$. Water and chloroform (Ajax Chemicals) were added to the supernatant with gentle mixing. The methanol-water layer was removed by a Pasteur pipette and the lipid-containing chloroform phase was retrieved.

The solvent was evaporated under a stream of $\mathrm{N}_{2}$. The residue was resuspended in PBS-BSA for testing in the splenectomized mouse assay or in a minimal volume of chloroform:methanol $(2: 1 \mathrm{v} / \mathrm{v})$ for characterization by thin-layer chromatography (t.1.c.). The samples were spotted onto silica-gel t.l.c. plates (silica gel, 0.2 mm thick: E. Merck AG, Darmstadt, West Germany) which had been previously washed with methanol. The plates were run in a solvent system of chloroform: methanol:water (65:35:4 by volume) (Lotner et al., 1980). Sections $(10 \mathrm{~mm} \times 3 \mathrm{~mm})$ of the chromatogram were scraped from the plate and suspended in chloroform:methanol $(2: 1 \mathrm{v} / \mathrm{v})$ to elute active fractions, and the silica was removed by centrifugation at $700 \mathrm{~g}$ for $10 \mathrm{~min}$. Each section was a progression of approximately $0.02 R_{\mathrm{f}}$ units. The eluting substances were dried under $\mathrm{N}_{2}$ and the residue was resuspended into $300 \mu \mathrm{l}$, PBS-BSA and tested in the splenectomized mouse system.

\section{Results}

Embryo culture medium induced thrombocytopenia $(P<0.01)$ in splenectomized mice while medium in which unfertilized eggs were cultured had no significant effect (Table 1). The plateletactivating effects of embryo culture medium were not altered by treatment with indomethacin or

Table 1. The relative change to the platelet count from splenectomized mice caused by: (1) culture medium in which unfertilized eggs were incubated; (2) culture medium in which 8-16-cell embryos were cultured for $24 \mathrm{~h}$ and (3) PBS containing $3.3 \mu \mathrm{g}$ PAF-acether $/ \mathrm{ml}$ and the effect of treatment of these fluids with various inhibitors of platelet activation

\begin{tabular}{lccc}
\hline & \multicolumn{3}{c}{ Platelet count relative to prior count (\%) } \\
\cline { 2 - 4 } Treatment & Control medium & Embryo medium & PAF-acether \\
\hline $\begin{array}{l}\text { Control } \\
\quad \text { untreated media) }\end{array}$ & $103 \cdot 1 \pm 4 \cdot 7$ & $72 \cdot 1 \pm 3 \cdot 1$ & $65 \cdot 3 \pm 8 \cdot 1$ \\
$\begin{array}{l}\text { Phosphoenol pyruvate } \\
\text { and pyruvate kinase }\end{array}$ & $106 \cdot 6 \pm 4 \cdot 9$ & $70 \cdot 6 \pm 5 \cdot 7$ & $63 \cdot 9 \pm 3 \cdot 8$ \\
$\begin{array}{l}\text { Indomethacin } \\
\text { Phosphoenol pyruvate/ }\end{array}$ & $101 \cdot 3 \pm 6 \cdot 1$ & $69 \cdot 0 \pm 2 \cdot 1$ & $61 \cdot 8 \pm 3 \cdot 8$ \\
$\quad$ pyruvate kinase and & & & \\
indomethacin & $104 \cdot 9 \pm 3 \cdot 6$ & $70 \cdot 2 \pm 2 \cdot 1$ & $67 \cdot 1 \pm 4 \cdot 3$ \\
\hline Control & $104 \cdot 7 \pm 3 \cdot 0$ & $72 \cdot 7 \pm 2 \cdot 9$ & $67 \cdot 1 \pm 3 \cdot 8$ \\
Chlorpromazine & $98 \cdot 7 \pm 4 \cdot 5$ & $90 \cdot 6 \pm 2 \cdot 3^{*}$ & $83 \cdot 3 \pm 3 \cdot 7^{*}$ \\
\hline Control & $101 \cdot 2 \pm 1 \cdot 9$ & $73 \cdot 5 \pm 3 \cdot 7$ & $68 \cdot 1 \pm 1 \cdot 2$ \\
Phospholipase A & $92 \cdot 1 \pm 6 \cdot 7$ & $91 \cdot 8 \pm 2 \cdot 3^{*}$ & $79 \cdot 9 \pm 2 \cdot 1^{*}$ \\
Phospholipase C & $106 \cdot 1 \pm 3 \cdot 2$ & $86 \cdot 5 \pm 3 \cdot 6^{*}$ & $78 \cdot 3 \pm 2 \cdot 7^{*}$ \\
Phospholipase D & $94 \cdot 7 \pm 4 \cdot 5$ & $93 \cdot 6 \pm 6 \cdot 4^{*}$ & $80 \cdot 1 \pm 3 \cdot 5^{*}$ \\
\hline
\end{tabular}

The results are the mean \pm s.e.m. of 3 replicates.

${ }^{*} P<0.05$ compared with control value (analysis of variance). 
Table 2. The platelet count of splenectomized mice after injection of the lipid fraction, before and after thin-layer chromatography (t.l.c.) of control and embryo culture medium and platelet-activation factor (in PBS containing $0 \cdot 25 \%$ BSA)

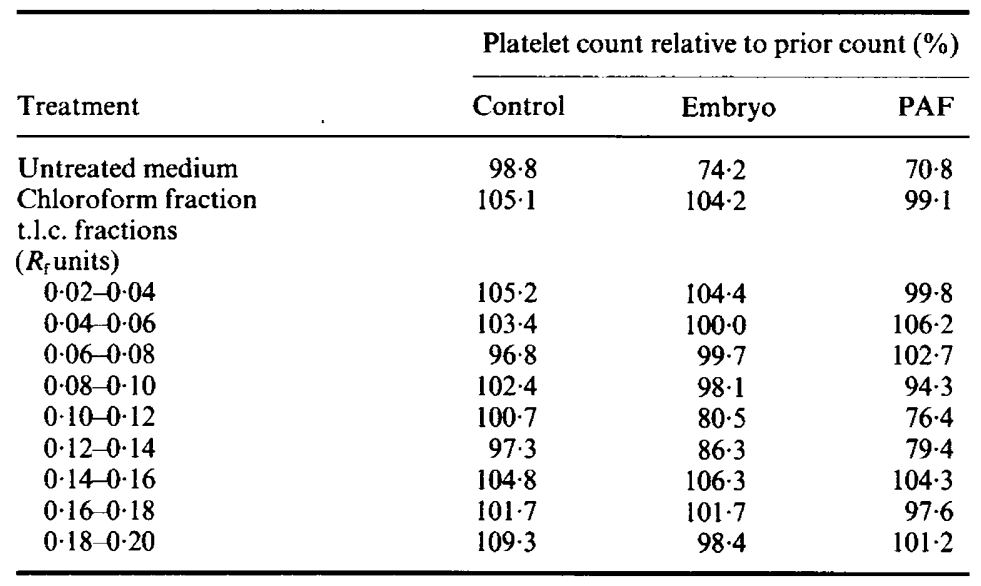

The results are the mean of 2 replicates.

the removal of ADP by phosphoenol pyruvate and pyruvate kinase (Table 1). Chlorpromazine caused a significant inhibition of the effects of embryo-derived PAF and PAF-acether (Table 1). Both substances showed a significant reduction in activity after treatment with phospholipase $A_{2}$, phospholipase $\mathrm{C}$ and phospholipase $\mathrm{D}$ (Table 1): lipase had no inhibitory effect on the activity of the embryo culture medium or PAF-acether.

The lipid fraction of the embryo culture medium contained all of the embryo-derived PAF. The identity of the factor was further characterized by t.l.c. The bulk of the activity migrated at $R_{\mathrm{f}}$ $0 \cdot 10-0 \cdot 12$ (Table 2). Synthetic PAF-acether displayed an identical profile (Table 2).

\section{Discussion}

Promoters of platelet activation are many and varied, but can be divided into a number of categories: (1) macromolecules, e.g. collagen; (2) enzymes, e.g. thrombin; (3) small molecules, e.g. adrenaline, ADP, PGs and PAF-acether; and (4) particles, e.g. antigen-antibody complexes and latex (reviewed by Holmsen, Salganicoff \& Fukami, 1977). Despite this array of known activators, they are all thought to act via one of three pathways (Haslam, 1964) which converge to give a single response. Such 'stimulus-response coupling' by platelets simplifies, to some extent, the study of the causes of platelet activation.

The three pathways of platelet activation are initiated by: (1) adenosine diphosphate (ADP) (Born, 1962); (2) the products of cyclo-oxygenase action on arachidonic acid (Vargaftig \& Zirinis, 1973); and (3) platelet-activating factor (PAF-acether) (Chignard, Le Couedic, Tence, Vargaftig \& Benveniste, 1979). In any particular circumstance it is possible to test which pathway is responsible by their sequential and concurrent inhibition. The ADP pathway is inhibited by the addition of phosphoenol pyruvate and pyruvate kinase which converts ADP to ATP (Born, 1962). The enzyme cyclo-oxygenase converts arachidonic acid to endoperoxide derivatives (Samuelsson, 1969) which cause platelet activation. This enzyme is inhibited by aspirin or indomethacin (Ferreira \& Vane, 1974) and so indomethacin blocks the second pathway of activation. The PAF-acether pathway is characterized by its property of causing platelet activation in the presence of inhibitors of the adenosine diphosphate- and cyclo-oxygenase-dependent pathways (Chignard et al., 1979). The 
involvement of this pathway is confirmed by examination of the biochemical properties of the activator, i.e. its sensitivity to phospholipases (Benveniste $e t$ al., 1977), its characteristic mobility during t.l.c. (Tence, Polonsky, Le Couedic \& Benveniste, 1980), and its inhibition by membraneactive drugs such as chlorpromazine (Cazenave, Benveniste \& Mustard, 1979).

The present results confirm earlier reports (O'Neill et al., 1985; O'Neill, 1985b) that the preimplantation embryo of the mouse produces a platelet-activating factor. It was previously reported that neither ADP nor arachidonic acid could mimic the effects of the embryo-derived PAF in the mouse bioassay (O'Neill, 1985b). In support of those findings, the platelet-activating effect of embryo culture medium was not altered by inhibition of the ADP and cyclo-oxygenase pathways of platelet activation (Table 1) and therefore did not appear to be acting along either of the first two pathways of platelet activation.

Embryo-derived PAF had a temporal profile of induction of thrombocytopenia in splenectomized mice that was similar to and a dose-response curve that was parallel to that caused by PAF-acether (O'Neill, 1985b). Both factors were partly deactivated by phospholipases $\mathrm{A}_{2}, \mathrm{C}$ and D but not by lipase (Table 1). The degree of deactivation was greater for embryo-derived PAF than for PAF-acether. This may suggest different chemical characteristics or it may be due to slight difference in concentration of the two chemicals. The dose-responses of both are relatively flat at these doses (O'Neill, 1985b) so that apparently similar doses may in fact be significantly different. Chlorpromazine caused a significant inhibition of the platelet-activating effects of embryo-derived PAF and PAF-acether (Table 1).

After chloroform:methanol extraction embryo-derived PAF and PAF-acether activity were found in the chloroform fraction and both factors displayed the same rate of migration $\left(R_{\mathrm{f}} 0 \cdot 10-0 \cdot 12\right)$ on silica t.l.c. (Table 2). Using the same methods, Lotner et al. (1980) showed that PAF-acether had an $R_{\mathrm{f}}$ value of $0 \cdot 10-0 \cdot 11$.

Insufficient material from the embryo culture medium has been collected to provide definitive chemical characterization of the platelet-activating factor produced by the zygote. Tence et al. (1980) proposed that if platelet activation occurs independently of the ADP and cyclo-oxygenase pathways and if the factor is partly purified and shown to migrate with characteristic mobility on t.l.c. or HPLC, that is sufficient evidence to assign the activation to the PAF-acether pathway. Embryo-derived PAF fulfils these criteria and it displays other chemical, biochemical and physiological similarities to PAF-acether.

PAF-acether is synthesized by the release of 1-0-alkyl-glycero-3-phosphocholine from phospholipids by phospholipase $A_{2}$ followed by the addition of the acetyl moiety of acetyl-coenzyme $A$ by acetyl transferase (Ninio, Mencia-Huerta, Heymans \& Benveniste, 1982). The preimplantation mouse embryo was capable of incorporating methyl- $\left[{ }^{3} \mathrm{H}\right]$ choline into phosphocholine, phosphatidylcholine and lysolecithins, via the Kennedy pathway (Pratt, 1980). Embryo extracts showed considerable phospholipase A activity, resulting in the deacylation of exogenous phospholipids (Pratt, 1980). Whether preimplantation embryos also contain an acetyl transferase capable of converting the lyso-phosphocholines into active PAF-acether is still to be determined. Preimplantation embryos, prelabelled with $\left[{ }^{3} \mathrm{H}\right]$ choline, lost $10-40 \%$ of labelled phospholipids during a 24 -h culture period and it was suggested that this was due to turnover of membrane phospholipids (Pratt, 1980). In view of the present findings, it will be necessary to perform pulse-chase studies to determine whether some of this label is released as embryo-derived PAF.

This work was supported by a Grant from the Australian Research Grants Scheme (ARGS).

\section{References}

Benveniste, J., Le Couedic, J.P., Polonsky, J. \& Tence, M. (1977) Structural analysis of purified plateletactivating factor by lipase. Nature, Lond. 259, $170-171$.
Born, G.V.R. (1962) Aggregation of blood platelets by adenosine diphosphate and its reversal. Nature, Lond. 194, 927-929.

Cazenave, J.P., Benveniste, J. \& Mustard, J.F. (1979) 
Aggregation of rabbit platelet by platelet-activating factor is independent of the release reaction and the arachidonate pathway and inhibited by membrane active drugs. Lab. Invest. 41, 275-285.

Chignard, M., Le Couedic, J.P., Tence, M., Vargaftig, B.B. \& Benveniste, J. (1979) The role of platelet activating factor in platelet aggregation. Nature, Lond. 279, 799-800.

Ferreira, S.H. \& Vane, J.R. (1974) Aspirin and prostaglandins. In The Prostaglandins, Vol. 2, pp. 1-34. Ed. P. Ramwell. Plenum Press, New York.

Haslam, R.J. (1964) Role of adenosine diphosphate in the aggregation of human blood-platelets by thrombin and by fatty acids. Nature, Lond. 202, 765-768.

Holmsen, H., Salganicoff, L. \& Fukami, M.H. (1977) Platelet behaviour and biochemistry. In Haemostasis: Biochemistry, Physiology and Pathology, pp. 239-319. Eds D. Ogston \& B. Bennett. John Wiley and Sons. London.

Lotner, G.Z., Lynch, J.M., Betz, S.J. \& Henson, P.H. (1980) Human neutrophil derived platelet activating factor. J. Immunol. 124, 666-684.

Ninio, E., Mencia-Huerta, J.M., Heymans, F. \& Benveniste, J. (1982) Biosynthesis of platelet activating factor. I. Evidence for an acetyl-transferase activity in murine macrophages. Biochim. Biophys. Acta 710, 23-31.

O'Neill, C. (1985a) Thrombocytopenia is an initial maternal response to fertilization in mice. $J$. Reprod. Fert. 73, 559-566.
O'Neill, C. (1985b) Examination of the cause of early pregnancy-associated thrombocytopenia in mice. $J$. Reprod. Fert. 73, 567-577.

O'Neill, C. \& Quinn, P. (1981) Interaction of the uterine flushings with mouse blastocysts in vitro as assessed by the incorporation of $\left[{ }^{3} \mathrm{H}\right]$ uridine. J. Reprod. Fert. 62, 257-262.

O'Neill, C., Pike, I., Porter, R.N., Gidley-Baird, A.A., Sinosich, M.J. \& Saunders, D.M. (1985) Maternal recognition of pregnancy prior to implantationmethods for monitoring embryonic viability in-vitro and in-vivo. Ann. N. Y. Acad. Sci. 680, (in press).

Pratt, H.D.M. (1980) Phospholipid synthesis in the preimplantation mouse embryo. J. Reprod. Fert. 58, 237-248.

Samuelsson, B. (1969) On the incorporation of oxygen in the conversion of $8,11,14$-eicosatrienoic acid to prostaglandin $\mathrm{E}_{1}$. J. Am. Chem. Soc. 87, 3011-3013.

Tence, M., Polonsky, J., Le Couedic, J.P. \& Benveniste, J. (1980) Release, purification and characterization of platelet-activating factor. Biochimie 62, 251-259.

Vargaftig, B.B. \& Zirinis, P. (1973) Platelet aggregation induced by arachidonic acid is accompanied by release of potential inflammatory mediators distinct from $\mathrm{PGE}_{2}$ and $\mathrm{PGF}_{2}$. Nature, New Biol. 244, 114-116. 